\title{
O desmonte da máquina- cinema: Pedro Costa e a estética do residual
}

\section{Osmar Gonçalves dos Reis Filho}

Universidade Federal do Ceará, Programa de Pós-Graduação em Comunicação, Fortaleza, CE, Brasil ORCID: https://orcid.org/0000-0002-3986-9008

\section{David leitão Aguiar}

Universidade Federal do Ceará, Programa de Pós-Graduação em Comunicação, Fortaleza, CE, Brasil

ORCID: https://orcid.org/0000-0001-9192-7626

\section{Resumo}

Ao termino de Ossos (filme de 1997), rodado nas Fontainhas, gueto lisboeta de cabo-verdianos, Pedro Costa percebe-se afetado por suas experiências no bairro e vê suas afetações não se concretizarem em suas imagens. Entre Costa e o fenômeno "Fontainhas" havia a máquina-cinema: um poder maquínico que desregula corpos e fenômenos e os recompõem num regime de imagens incapaz de dar forma visual às realidades residuais. Segundo pesquisadores que dialogam com a teoria das imagens - Jean-Louis Comolli, Gilles Deleuze, Giorgio Agamben, Vilém Flusser, entre outros - as tecnologias de poder, e aqui ressaltamos os dispositivos midiático-imagéticos, administram a produção simbólica de uma realidade determinada, e têm por estratégia produzir subjetividades subservientes (ou dessubjetivações) em proveito de um determinado projeto político. Apostamos que Costa, sobretudo em Juventude em marcha (filme de 2006), ao estabelecer um método políticoestético para um subversivo regime de imagens, sua estética do residual, agenciará uma série de estratégias para efetuar um desmonte - ao menos uma remontagem - da máquina-cinema.

\section{Palavras-chave}

Pedro Costa. Máquina-cinema. Imagens técnicas.

Dessubjetivação. Estética do residual.

\section{1 "Este não é o meu país. Meu país é Fontainhas"}

Retornando de Cabo Verde, onde realizou Casa de lava (1994), rodado em Tarrafal na ilha de Santiago, antiga Colônia Penal da Morte Lenta ou campo de concentração para os 
presos políticos do regime salazarista ${ }^{1}$-, o cineasta português, Pedro Costa, passará a ocupar-se em suas próximas obras das vivências do bairro lisbonense das Fontainhas gueto de subproletariados e alguns toxicodependentes que foi constituindo-se por refugiados e imigrantes das colônias portuguesas, sobretudo de Cabo Verde. Nas Fontainhas, Costa depara-se com experiências que marcariam sua filmografia: o verdadeiro estado de exceção em que viveram e ainda vivem os cabo-verdianos, os quais, em busca de condições de sobrevivência, passaram a subsistir em Portugal como mão de obra quase escrava, confinados no isolamento dos guetos lisboetas.

Em certa medida, não estariam os métodos da plantation ${ }^{2}$ sendo renovados pelo Estado fascista de Salazar, e, posteriormente, também pelo regime capitalista do Estado democrático de direito? Costa irá explorar e desnaturalizar tais contradições em seus filmes. Um processo de desmonte que não se dará apenas em uma única obra, mas ao longo de sua filmografia, particularmente em Juventude em marcha (2006). E sobre tal poder técnico, estético, maquínico, Comolli nos sugere suas primeiras impressões:

Como não supor alguma conveniência secreta dos dois sistemas maquínicos - aqueles que desregulam os corpos, aquele que os regula? [...] 0 fato de a máquina-cinema fabricar para nosso uso uma outra percepção do espaço e do tempo que não aquela(s) que acionamos em tantas outras experiências sensíveis induz um tipo de poder não humano ou extrahumano da máquina cinematográfica. (COMOLLI, 2008, p. 74-75).

Ao final de Ossos (1997), rodado quase exclusivamente nas Fontainhas e tendo como atores diversos moradores do gueto lisboeta, Costa depara-se com eventos que lhe desestabilizam: o que podem os dispositivos de tecnoimagens perante fenômenos dilaceradores como as distopias das Fontainhas? Dessa forma, se faz necessário que nos questionemos: em qual medida o poder extra-humano da máquina-cinema turva as imagens e as hierárquicas relações de poder entre aqueles a quem se toma as imagens e aqueles que as toma? E como nos depararmos com os dispositivos sem observar que estes são fenômenos numa árdua relação de poder?

\footnotetext{
${ }^{1}$ Entre 1926 e 1974, Portugal viveu o regime de cunho fascista do Estado Novo, também conhecido como salazarismo, dada a personificação do Estado português pela representação de Antônio de Oliveira Salazar. A política salazarista impôs duríssima repressão tanto em Portugal quanto nas colônias ultramarinas na África.

2 Processo colonial de produção econômica do século XV baseado na escravização de povos originários de seus continentes e africanos capturados e forçados a servir como mão de obra escrava na agricultura como fonte primária de capitalização. Regime cujos corpos explorados transitam entre os insumos de um empreendimento econômico - os corpos insumos - e a posse, matabilidade e extermínio - os corpos matáveis.
} 
A crítica de Vanda a Pedro Costa, ao final de Ossos (1997), afetou o realizador de forma contundente para que este repensasse a sua relação com os fenômenos em questão: "Vanda veio ter com ele e perguntou-lhe se o cinema tinha que ser sempre assim, tão difícil, com tanta gente, tanto balbucio, tanta maquinária" (CABO, 2009, p. 24). Dito isso, se faz necessário observarmos que Vanda Duarte é uma moradora das Fontainhas e interpretou, como uma atriz não profissional, a personagem ficcional, Clotilde. Em No quarto da Vanda (2000), Pedro Costa documenta a auto-mise-en-scène de Vanda. Enquanto esta faz uso excessivo de heroína e destila sua falta de expectativas, Costa resume sua maquinária a uma pequena câmera de vídeo, um reduzido equipamento de som e passa a conviver todos os dias, durante mais de nove anos, com os moradores das Fontainhas, escutando seus traumas, inventariando vestígios e experiências em seu novo processo de criação artística. E em tal problematização, Vanda critica a maquinária de Costa. Percebe que seu corpo, sua voz, sua história, estão um tanto desregulados, lhe são impostas marcas ficcionais - a máquina-cinema parece rejeitar, em alguma medida, certas mise-en-scènes -, existem faltas e excessos que a máquina-cinema pode ter transfigurado em Ossos (1997).

Vanda Duarte tinha sido em Ossos a mais relutante a seguir as instruções do realizador, a mais resistente às ordens [...] 'Não havia maneira de fazê-la dizer o que eu queria nem fazê-la ir as marcas'. Pedro Costa começou então a pensar - há uma entrevista em que diz a 'sonhar' - 'se o cinema não se fez para as pessoas dizerem o que querem dizer, para as pessoas fora das marcas'. (CABO, 2009, p. 24-25).

Vanda compreendia o que a cinematografia não captara: mesmo sendo-lhe impostas novas margens pelas relações de poder que orbitam um conjunto de aparatos técnicos, ainda assim as tecnoimagens poderiam dar mais e recompor seu corpo e seu ser - dar-lhe formar visual - que sempre foram dilacerados por dispositivos. Poderia Vanda resistir e apenas dizer não; possivelmente já o fez de outras maneiras, mas ali ela percebeu algo mais. Provavelmente havia fissuras nos dispositivos e nas relações de poder em jogo por onde passavam a regulação de muito do que lhe foi tomado; Vanda poderia ser recomposta e Costa assume o enfretamento de tais relações. Nesse gesto, podemos identificar forte indício das relações de poder que orbitam, encrustam-se e acabam por emanar da máquina-cinema. Estariam estas mesmas estratégias de biopoder e necropolítica ${ }^{3}$, tão presentes em

\footnotetext{
3 Tendo como base o biopoder pensado por Foucault, a necropolítica caracteriza-se por um novo estágio da biopolítica, agora centrado na produção da morte em larga escala, característica de um mundo em crise sistêmica.
} 
diferentes tecnologias de poder - seja a força policial, os mecanismos do mercado financeiro, judiciário, midiático (FOULCAUT, 2018) -, também presentes no vasto conjunto de dispositivos que compõem a máquina-cinema?

\begin{abstract}
Essa captura do outro é insuportável [...] depois do filme ele vai se olhar ou se encontrar preso no olhar dos outros espectadores, e então será visto como ele não se vê [...] temo que os cineastas que se dizem e se colocam em posição de "dar" [...] não façam mais do que ocupar novamente o lugar do mestre, reproduzir o gesto de poder. Pois não se trata de "dar", mas de tomar e de ser tomado. Trata-se sempre de violência: não de restituir a algum despossuído o que eu teria decido e decidiria que lhe faz falta, mas de constituir com ele uma relação de forças em que, seguramente, arrisco ser tão despossuído quanto ele. (COMOLLI, 2008, p. 70-74).
\end{abstract}

Portanto, o fato de Costa, naquele momento, se desnudar de uma maquinária ostensiva, como logo veremos, é um gesto violento de remontar uma relação de poder com os fenômenos "Vanda e Fontainhas", de negociar a imagem sem estar armado com uma determinada máquina de poder. Desnudo, Costa passa a observar a mise-en-scène que Vanda reclama para si e nisto consiste uma relação sempre negociada. Com efeito, percebemos indícios um tanto sólidos que nos fazem apostar numa possível conceituação acerca da máquina-cinema: um vasto conjunto de dispositivos e aparelhos de uma tecnologia de poder que produz um dado regime de imagens que tem por estratégia "corrigir" determinadas realidades sociais - a violência da produção residual de refugo humano (BAUMAN, 2005), por exemplo -, ou como propõe Comolli (2008), desregulando e regulando os fenômenos para si, como melhor convir e for possível, em acordo com as estratégias do projeto econômico liberal. E trilhando tais perspectivas, não podemos deixar de atentar a proposição de que assim como o capitalismo não apenas produz produtos para os consumidores, mas, sobretudo, consumidores para seus produtos, como constatara Marx (1999), o filósofo alemão nos sugere um dos pressupostos que os sistemas disciplinares de Foucault e os sistemas de controle de Deleuze terão como pilar em seus modos de efetivação dos poderes dos dispositivos; a produção de subjetividades engajadas em uma determinada estratégia hegemônica, mesmo no campo da produção das subjetividades:

A produção não produz, pois, unicamente, objeto para o consumo, mas também o modo de consumo, ou seja, não só objetiva, como subjetiva [...] o objeto de arte, tal como qualquer outro produto, cria um público capaz de compreender a arte e de apreciar [...] portanto, a produção não cria 
somente um objeto para o sujeito, mas também um sujeito para o objeto. (MARX, 1999, p. 32-33, grifo nosso).

Enfim, o sistema produtivo estabelece uma relação que objetifica o sujeito e suas subjetividas em proveito da produção do mercado de objetos. Dessa forma, parafraseando Marx, não poderíamos sugerir que a máquina-cinema, portanto, não apenas produz imagens do mundo, mas, sobretudo, um mundo sob um específico regime de imagens? Em tal perspectiva, propõe Peter Pál Pelbart:

\begin{abstract}
Através dos fluxos de imagem, de informação e de conhecimento que acessamos constantemente, absorvemos maneiras de viver, sentidos de vida, consumimos toneladas de subjetividade. Chama-se como se quiser isto que nos rodeia, capitalismo cultural, economia imaterial, sociedade do espetáculo, era da biopolítica, o fato é que vemos instalar-se nas últimas décadas um novo modo de relação entre o capital e a subjetividade. 0 capital, como disse Jameson, por meio da ascensão da mídia e da indústria da propaganda teria penetrado e colonizado um enclave até então aparentemente inviolável, o inconsciente. (PELBART, 2013, p. 20).
\end{abstract}

Debruçando-se especificamente na interseccionalidade, economia-política, sistemas de controle, produção de imagens contemporâneas, Vilém Flusser (2011a) exuma a câmera fotográfica como o protótipo de uma rede de aparelhos de imagens técnicas reprodutoras de vetores de poder que pressupõe uma programação prévia e que se propõe a controlar, administrar e produzir seu indivíduo, cuja redundância das informações e da modelagem de realidades é estratégia basilar. Costa - em relação à tal perspectiva cuja máquina-cinema teria a capacidade de produzir simbolicamente um mundo em estufa -, se contrapõe e passa a escavar os vestígios das experiências dos corpos residuais do depósito das Fontainhas, singularizando vidas que foram expelidas para as margens do social e do imagético. Costa já não está a uma distância margeada por marcas impostas aos corpos, mas sentado dentro do quarto de Vanda, observando bem próximo, ou ao alcance das mãos de Ventura a perder-se em meio aos detritos de sua moradia.

Nosso gesto metodológico é uma análise de sobrevoo, uma análise panorâmica, não se tratando de um estudo pormenorizado dos filmes. 0 que nos interessa é o processo de confronto/desmonte/remontagem da máquina-cinema que se dará ao longo de sua filmografia, reconhecendo em Juventude em marcha (2006) uma centralidade em nossas questões. Fato que se deve ao percebermos que o gesto de Costa passa - de forma bastante exemplar nesta obra -, inevitavelmente, por um saber-montagem, um saber-colagem, um 
saber-movimento, de tempos, vestígios e afecções intempestivos, que se justapõem e se aproximam. Nosso método espelha, em certa medida tais gestos, trabalhando com fragmentos dos diversos filmes, para observar uma questão mais ampla.

Com efeito, em No quarto da Vanda (2000), Costa começa a desmontar a máquinacinema. Será, contudo, preciso uma série de experimentos técnicos e estéticos para que ele constitua as bases de sua remontagem consumadas em Juventude em marcha (2006). Quanto a isso, Benjamin alertara que do programa liberal "se podia esperar não somente a exploração crescente do proletariado, mas também [...] a criação da sua própria supressão" (1996, p.165), portanto as bases para a supressão desse regime de imagens estão dispostas nos detritos e contradições das quais ela participa da produção ao longo da história - o colonialismo do século $\mathrm{XV}$, o neocolonialismo salazarista, ou as técnicas camufladas do neoliberalismo, etc. Nisso consiste parte de nosso método: é preciso escutar as ruínas, como as imagens de Costa em Juventude em marcha (2006) que se detêm em vestígios de fenômenos e seus detritos, escavar cada detrito para conhecer sob quais circunstâncias foram criados e quais potências de pathos ali ainda sobrevivem, como é possível materializar tais sobrevivências e auscultar as diferentes qualidades sígnicas dos vestígios; portanto, olhar atentamente para a estética do residual de Pedro Costa:

\begin{abstract}
Agora, em geral, o mundo é uma encenação muito má [...] eu não quero entrar nessa encenação. 0 que senti é que num bairro como esse, se levasse para ali o Cinema, ia levar outra espécie de Polícia. Eu não sou a SIC, nem a TVI ou a RTP, que vi muitas vezes entrarem lá 30 minutos para falar com uma velhinha ou com um puto que acha que conhece o gajo que matou e que fugiu da polícia. 0 meu trabalho é ficar lá um bocadinho mais e ver como é que aquilo funciona. Como fiz isso, percebi que aquilo é um sítio completamente explorado pelo governo, pela falta de emprego, pelo racismo, pela falta de oportunidades e até por eles próprios. (POIARES; SILVA, 2010, grifo do autor).
\end{abstract}

\title{
2 A máquina-cinema e os corpos dóceis
}

Segundo Jean-Louis Comolli (2008), as relações sociais dão-se em auto performances previamente estabelecidas ou demasiadamente encenadas e roteirizadas, produção serializada da redundância: propósito liberal que necessita antecipar seus resultados e será, primeiramente o Estado, a tentar provir o mercado desse controle dos resultados para garantir o laissez faire econômico. É, portanto, administrada por um aparato de tecnologias de poder. 
É preciso compreender que os dispositivos têm sua genealogia fundada na necessidade de um dado momento histórico como resposta de uma urgência por meio de uma função eminentemente estratégica (AGAMBEN, 2009). 0 primeiro mágico, feiticeiro e artista foi justamente aquele que percebeu que no seio de seu medo - a natureza encontravam-se os meios de enfrentamento e sobrevivência: "O homem tornou-se homem através da utilização de ferramentas" (FISCHER, 1987, p. 21). E ele imbui a ferramenta de um propósito anterior à sua fabricação; fabrica-o na medida que projeta a modificação do mundo. Os atuais dispositivos não teriam princípios semelhantes? Esse repetir de gestos por acréscimos é um capturar e diferenciar fenômenos, sistema perceptivo que, ao projetar seus propósitos, cria uma sistematização lógica. Portanto, “a linguagem surgiu juntamente com os instrumentos" (FISCHER, 1987, p. 30). A linguagem foi, dentre todas, a ferramenta primordial que mudou as relações de poder entre homem e natureza. "Um gesto, uma imagem, um sim, uma palavra - era tão instrumento como o machado ou a faca [...] modo de estabelecer poder do homem sobre a natureza" (FISCHER, 1987, p. 40).

A máquina-cinema teria por estratégia o processo de desregular/regular os fenômenos adaptando-os razoavelmente aos seus propósitos de resultados por antecipação, protegendo a linguagem de um dado sistema econômico de uma ruptura em sua estratégia: o dispositivo máquina-cinema seria uma gigantesca rede de infraestruturas extremamente inflacionadas de superestruturas (FLUSSER, 2011a), máquina reprodutora de imagens préestabelecidas e razoavelmente condicionadas às informações redundantes desta, na qual o real seria expelido em prol de uma produção industrial de subjetivações. Comolli afere que as imagens desse poder maquínico tendem a arrefecer as experiências traumáticas tão próprias do projeto civilizatório liberal, produzindo um sistema tautológico de experiências sociais, um mercado de trocas de informações inflacionadas e redundantes. Quanto a isso, Costa nos apresenta mais indícios de suas percepções acerca do conflito com os poderes da máquina-cinema:

É uma forma de conseguir tocar na câmera [...] quando comprei a minha, fui para o bairro, li o livro de instruções e comecei a filmar. Eu, com as mãos. E isso mudou mesmo muita coisa. Acho que hoje em dia, o mundo da arte, da cultura vive muito da inflação [...] e essa inflação ia juntar-se a outras inflações orçamentais e tive muito medo que a essa inflação, se juntasse uma estética ou artística. Às tantas, temos uma espiral progressiva. (POIARES; SILVA, 2010). 
Há nesse gesto uma tentativa de aproximar-se dos fenômenos, tocá-los com as mãos e impedir que a máquina-cinema turve, inflacione ou discipline suas imagens. Costa não poderia deixar passar despercebido a singularidade do ecossistema das Fontainhas e o modo pelo qual os dispositivos imagéticos configuram as relações de poder sobre as vidas residuais. Não é uma relação de "dar" voz e representatividade ao corpo filmado, sendo esta uma relação de poder minoritariamente prevista no programa, mas de desnudar-se da maquinária ostensiva para negociar um novo tipo de relação de trocas. Portanto, em Juventude em marcha (2006), haveria de ser um tanto diferente tais hierarquias, era preciso que as subjetividades de Ventura, Vanda, Clotilde e tantos, tivessem direito aos seus devidos lugares de existências, em suas verdades e tragédias. E tudo passava por uma mudança na relação biopolítica com os dispositivos maquínicos. Era preciso fazer filme sem levar o "Cinema" e Costa tinha a compreensão de que o "Cinema" era um poder comparável a coerção policial - já tão habituado em colocar aqueles corpos em marcas roteirizadas.

Michelle Sales observara em seu artigo, 0 cinema e o direito a morte (2019), certa relação paternalista e eurocêntrica, especialmente em Casa de lava (1994) e Ossos (1997). Em ambos, enfermeiras do mundo dito "civilizado", ora conduzem a narrativa enquanto adentramos em regiões fronteiriças e marginais - Cabo Verde e Fontainhas, respectivamente -, ora adotam um tom um tanto estereotipado (SALES, 2019) de um paternalismo salvador perante um povo explorado e "incivilizado". É bastante significativo o fato de serem enfermeiras: o Estado representado por meio de saberes e poderes constituídos acerca da vida e da morte. Constatamos, em ambos os casos, que Costa ainda mantinha relações de poder bastante hierárquicas. A máquina-cinema - aparelho programado por uma determinada linguagem-estratégia - não estaria realizando uma mediação, cuja um dos princípios seria impor tal relação de poder hierárquica?

E, no entanto, podemos constatar em Juventude em marcha (2006) uma relação com o saber/poder "medicina", totalmente diferenciado: demoramo-nos longamente a escutar Vanda, em sua nova habitação social no Casal da Boba, como um corpo residual, refugo da produção industrial capitalista, que despeja sobre nós seus traumas quanto a sua toxicodependência e seu profundo mal-estar quando internada em um hospital lisboeta durante sua gestação e parto. Os cuidados médicos lhes marcaram como uma agressão física. A câmera de vídeo não privilegia elementos específicos do quadro senão o despojamento e acaso de sua moradia e o corpo de Vanda que denota, ao longa de sua narração, seu profundo mal-estar, como sintomas latentes que emergem, um prático 
procedimento de sua estética do residual. Costa desinflaciona a mise-en-scène e tenta produzir um novo equilíbrio de forças entre quem se dá a imagem e quem filma. Quando relata que não poderia levar o Cinema para dentro dos guetos de Lisboa, sinaliza enfaticamente um novo procedimento fílmico que percebe quais poderes estão em questão na máquina-cinema e em uma série de dispositivos, cuja suas personagens estão em disputa.

Acerca dos poderes sobre a vida e a morte, Agamben (2012, p. 09) lembra-nos sobre o duplo sentido da palavra vida para os gregos: "zoé que exprimia o simples fato de viver, comum a todos os seres vivos e bíos, que indicava a maneira de viver própria de um indivíduo ou de um grupo", modo de diferenciação por certa qualificação da vida ou dos seres viventes. "Temos assim duas grandes classes, os seres viventes (ou substâncias) e os dispositivos. E, entre os dois, como terceiro, os sujeitos. Chamo de sujeito o que resulta da relação corpo a corpo entre seres viventes e os dispositivos" (AGAMBEN, 2009, p. 41).

Respondendo a criação de uma função estratégica dos dispositivos, Deleuze (2015) propõe uma topografia de linhas, vetores ou feixes de luz de subjetivação, os quais partem de um dispositivo para outro em um fluxo de mão dupla e cujo ser vivente encontra-se no fogo cruzado de tais feixes. Em sua topografia ele categoriza, dentre outras, linhas que se curvam (fissuram a estratégia de controle e administração dos seres viventes, podendo gerar uma subjetivação ingovernável), e linhas que retificam as anteriores (reestabelecem a estratégia de governança dos corpos), no que chamamos atenção às linhas de dessubjetivação (uma linha de retificação para uma governança totalitária). 0 sujeito agora está sob ameaça dos feixes de retificação e dessubjetivação:

Acabar com a experiência, com a iniciação com a transmissão significa [...] acabar com a dimensão do sujeito. Que entulha a economia de mercado. 0 sujeito perturba a cibernética geral [controle dos modos e das máquinas de comunicação e distribuição da informação - técnica maquínica do governo de massas]. (COMOLLI, 2008, p. 103, grifo do autor).

As experiências e subjetivações do sujeito residual fissuram as linhas de dessubjetivação. Agamben então implica que a dessubjetivação é um radical processo cujo resultado é a alienação decisiva do sujeito para com os fenômenos, feixes de luz (DELEUZE, 2015) que nos direcionam (retificam) a um governo totalitário, produtor de corpos dóceis ao capitalismo que se fazem refém de uma linguagem, e neste sentido não esbarramos na máquina-cinema por um acaso, ponto de convergência entre a polícia e as tecnoimagens. 
Figura 1 - Arquitetura: ruínas das Fontainhas ${ }^{4}$

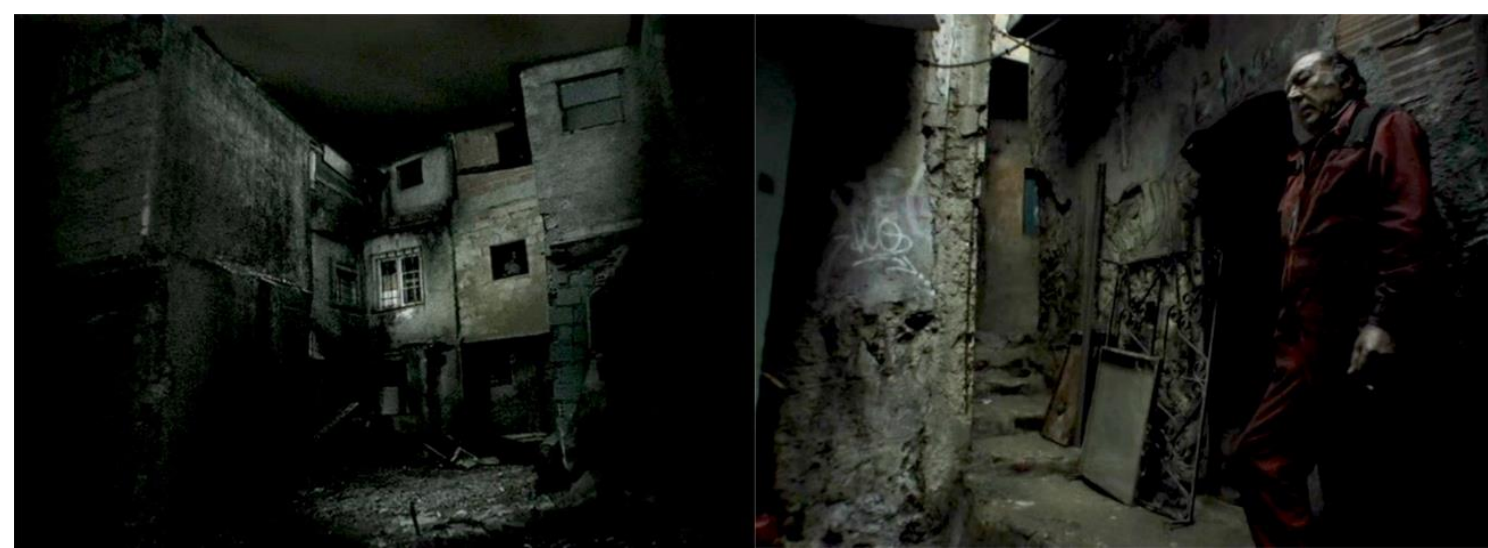

Fonte: Juventude em marcha (2006).

Tudo isso nos faz retornar ao sujeito que causa distúrbios na técnica maquínica do governo de massas (COMOLLI, 2008), são os sujeitos com os quais Costa se depara nas Fontainhas: se tal projeto prevê a produção de seres residuais, também prevê um depósito de refugo humano (BAUMAN, 2005). É nesta medida em que Costa se depreende com as Fontainhas, o bairro de lata é a um só tempo, um depósito residual dos detritos gerados pelo processo capitalista e um contradispositivo capaz de produzir subjetividades de corpos ingovernáveis, que, como efeito colateral, se opõem aos corpos dóceis - aliás, Deleuze imaginava Atenas como um gigantesco dispositivo. Se Costa deparou-se com o dispositivo máquina-cinema e percebeu que este tinha a capacidade de retificar as linhas curvas de subjetivação, Fontainhas era por si um contradispositivo subjetivador, que poderia anular as linhas de retificação - senão, fissurá-las - e caberia ao realizador lusitano encontrar uma forma de captar os feixes de luz que se curvam e fissuram emanadas das Fontainhas e seus corpos. 0 Cinema não poderia entrar em Fontainhas como uma nova Polícia e suas linhas de poderes retificadores, como ele constatara, e num pequeno gesto Costa propõe uma subversão: uma troca na hierarquia de forças, cujo dispositivo Fontainhas há de fissurar as linhas retificadoras da máquina-cinema.

Diante de tal panorama torna-se inevitável nosso encontro com o pensamento de Vilém Flusser. O filósofo tcheco (2011a) tensiona as imagens tradicionais e as imagens técnicas, ambas seriam ontologicamente opostas: as imagens tradicionais têm por pressuposto a magia de primeira ordem, que visa entronizar no homem um poder mágico de modificar o mundo; as tecnoimagens são uma magia de segunda ordem, que tem por

${ }^{4}$ Fontainhas em Juventude em marcha (2006). 
propósito, não modificar o mundo, mas controlar o homem. Um poder proveniente de uma programação que produz, controla e administra, seu indivíduo, mantendo o mundo numa realidade em estufa de redundâncias. Aqui redundância, assim como em Comolli, tem uma função-poder imprescindível de produção e administração da realidade.

Constatamos que a máquina-cinema coincide com tais estratégias, programas e poderes maquínicos observados por diferentes pesquisadores, um aparelho, máquina ou dispositivo regulado seja pela invisibilidade de sua programação ou pelo enunciado não dito (AGAMBEN, 2009). A contemporaneidade pós-industrial, investindo neste mesmo programa, possui uma coleção de dispositivos e terminais cibernéticos que realizam o mundo dentro de previsões programadas, fluxo ininterrupto de produção circular cuja cada aparelho nos conduz fatalmente a outro: máquina-cinema, terminais de exibição, críticos, curadores e festivais, indústria da propaganda, máquina-cinema, parques industriais, tecnologias da morte, necropolítica, bolsa de valores, programação circular. E, no entanto, a mise-en-scène de Costa é uma modulação de acasos; compartilhar determinada mise-enscène de corpos ingovernáveis como Vanda e Ventura é apostar no imprevisto. Costa utilizase deste maquinário subvertendo-o. E nisto Flusser compreende consistirem os levantes contra o programa:

1. 0 aparelho é infra-humanamente estúpido e pode ser enganado; 2 . Os programas dos aparelhos permitem introdução de elementos humanos não previstos; 3. As informações produzidas e distribuídas por aparelhos podem ser desviadas da intensão dos aparelhos e submetidas a intensões humanas; 4. Os aparelhos são desprezíveis. Tais respostas e outras possíveis, são redutíveis a uma: liberdade é jogar contra o aparelho. E isto é possível. (FLUSSER, 2011a, p. 106).

\section{Inventário de poesia, barbárie e memória}

Em sua crítica da cultura, Benjamin (2009) insiste numa "arqueologia material", que implica no método do materialismo histórico. Sob a potência da matéria e das ruínas escondem-se histórias e sensibilidades. E assim como Fontainhas é demonstrada aqui como um contradispositivo subjetivador, não seria o bairro de lata um sítio arqueológico de materialidades e sensibilidades prenhes de histórias que a cultura ocidental hegemônica exila de suas experiências? Parece-nos que Costa assim percebe.

Ao término de Ossos (1997), Vanda, sua personagem, pergunta se seria preciso tanta parafernália para se fazer cinema, posto que as histórias estavam ali nas Fontainhas ou 
mesmo em seu quarto - ela mesma como um vestígio a ser escavado - e não em seus aparatos técnicos (CABO, 2009). Passará então a conviver todos os dias com os moradores das Fontainhas, a tomar notas das dores e experiências ou vaguear observando muito atentamente ao que pode ser um vestígio ignorado, como um flâneur.

É a vida que intervém no cinema e não o oposto. Há qualquer coisa maior do que nós que tem de ser posta à prova [...] quando gravo no bairro, é chegar de manhã, como se fosse o meu estúdio [...] portanto, quando digo: "lembras-te desse dia em que a tua mãe morreu?" e a resposta dele é "lembro-me", sei que aquilo nos vai dar assunto para um ano [...] e não me importo de estar um ano a falar disso com ele, até conseguir dizer aquilo que tem a dizer (POIARES; SILVA, 2010, grifo do autor).

Costa subverte aqui mais um termo da máquina-cinema: segundo Flusser (2011a) as tecnoimagens pressupõe uma magia de segunda ordem, que tem por função ontológica intervir e controlar o sujeito, e não o mundo. Por sua vez, Costa sabe dos imensos inflacionamentos a que tais estratégias têm levado as imagens, agora é preciso perceber que a vida existe fora das imagens e que existe uma vida ingovernável. Ele inverte a hierarquia de poder da visibilidade e coloca a vida, particularmente as vidas residuais, em seu devido lugar: "É a vida que intervém no cinema e não o oposto".

Em No quarto da Vanda (2000) e Juventude em marcha (2006), as marcas de confinamento dos corpos explorados pelo neocolonialismo salazarista e pelo Estado neoliberal, passam a ser apagadas com a destruição do bairro. Seus habitantes são levados para novas moradias insípidas, o Casal da Boba; verdadeiro abismo de memórias. Será notável em suas novas imagens, ou seja, em sua estética do residual, a forte presença da vida secreta e silenciosa dos vestígios: em No quarto da Vanda (2000), eram as máquinas do Estado a despedaçar e apagar Fontainhas, enquanto Paulo, o coxo, e Nhurro, se injetavam e raspavam as sobras de heroína sobre a mesa e tudo na mais perfeita naturalidade. E estes mesmos homens-resíduos, em sua exclusão social com escalpes pendurados, em sua autoimolação na toxicodependência, dão de ombros às escavadeiras e seus funcionários, estes, por sua vez, em pacto tácito, ignoram o que falam os escombros, as memórias e os corpos imolados dentro das toscas ruínas em processo de apagamento. Tudo muito natural: enquadramento fixo em planos-sequência de cenas de tempos mortos, silêncios que se demoram, uma câmera que observa gestos minimalistas; nem sentimentalismo, nem sensacionalismo, teria, inclusive, pouco a se opor à máquina-cinema se caso não fosse a 
contradição da qualidade dos vestígios postos em quadro, feita numa escolha minuciosa e desconcertante. Acrescentamos que em Juventude em marcha (2006) as ruínas saltam ainda mais nas imagens, seja pelo tempo que se demoram no ecrã, seja por vê-las por toda parte e nas mais variadas formas, justapostas a outras tantas potências de vestígios.

Esse é o processo da estética do residual de Costa, ou em suas palavras, seu trabalho é ficar lá um tempo mais e ver como é que aquilo funciona, colher paciente e cuidadosamente signos-resíduos, realizar seu inventário de vestígios materiais ou imateriais - passar anos a escutar os traumas-memórias de Vanda, Clotilde, Ventura, Lento, etc. -, negociar e dar forma visual a estes vestígios. Então ele inventaria, seleciona e põe em confronto os vestígios numa montagem de crises: seja na crise que emerge do medo de Ventura quanto a Revolução dos Cravos contra o salazarismo seja confrontando o Estado democrático liberal que exerce sobre estes corpos uma violência semelhante ao regime de exceção português, crises da história que se repetem em modelos aparentemente diferentes, mas que apanhados dos traumas de suas personagens e justapostos na montagem de tempos e crises, seja em Juventude em marcha ou em Cavalo Dinheiro (2014), Costa nos faz retornamos a constatar Benjamin: "A tradição dos oprimidos ensina-nos que o 'estado de exceção' em que vivemos é regra" (BENJAMIN, 2010, p. 13, grifo do autor).

Em Juventude em marcha (2006), suas personagens estão sendo realocadas para suas novas moradias: o Casal da Boba. Conjuntos habitacionais, sem as marcas dos terríveis detritos que codificavam material e sensivelmente suas existências. Quanto a isto uma nova situação requer de Costa uma percepção mais atenta do que e como falam os vestígios, um processo de composição imagética sob um choque de montagem dialética ainda mais intensa, e sob os escombros e sombras do que restou das Fontainhas, surge Clotilde, fantasmagoricamente, com uma faca na mão. Ela deixa que venha à tona lembranças e associações livres:

Eu era menina. Entrava na água. Tinha o corpo como o de um peixe. Tinha os ombros mais largos do que qualquer rapaz em San Felipe [...] nenhum deles tinha coragem para me seguir. Eles ficavam na praia gritando [...] "Tubarões, Clotilde! Volte antes que eles te comam!"[...] as vezes eu levava o meu filho mais velho. Eu o deixava nas pedras e mergulhava na água. Eu queria não voltar nunca mais. (JUVENTUDE EM MARCHA, 2006). 
Figura 02 - Arquitetura e refugo humano ${ }^{5}$

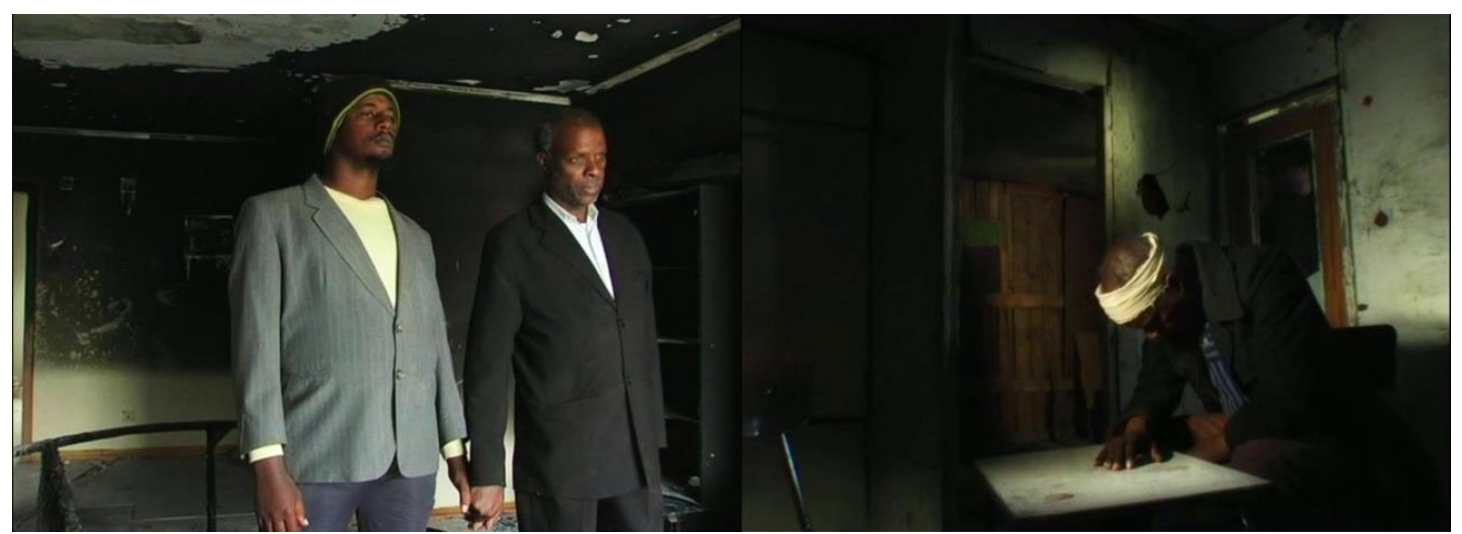

Fonte: Juventude em Marcha (2006).

Clotilde se recusa a abandonar Fontainhas e simplesmente some. E, no entanto, permanecerá onipresente em cada quadro de Juventude em marcha (2006). Clotilde parece se fazer Fontainhas, fundir-se às ruínas e sombras que lá ainda restam. Entre a existência material e imaterial, Clotilde, em sua recusa e resistência, mergulha nos escombros das Fontainhas para nunca mais voltar e a imagem de suas simples palavras tão plenas de violência continuará indissociável de cada ruína enquadrada. Em Clotilde, Costa percebeu pequenos fragmentos de vestígios aparentemente desconexos que ele colhe em seu inventário, mas que em sua montagem, ora de uma composição material, ora de uma memória que resiste, o escavador lusitano justapõe tais fragmentos em prol de uma montagem de crises que se encontram, seja nas diferentes qualidades materiais, seja na descontinuidade temporal de como as memórias emergem. A partir de Juventude em marcha (2006), a irrupção anacrônica impõe potências e novas qualidades de vestígios imateriais em sua mise-en-scène.

Bete, juntamente com seu pai, Ventura, deitada sobre uma cama, observa os seres que habitam suas decrepitas paredes: o policial, o leão, etc. Lento, consumido pela brancura do Casal da Boba e seu apagamento memorial, decide chamuscar de negro essa mesma brancura: em uma tentativa de suicídio abortada, ele incendiara a nova casa com sua família dentro. Lento, tem agora de volta as marcas que lhe são de direito, mesmo que preferisse não as ter. Lento assume seu lugar de corpo ingovernável. Então aperta a mão de Ventura e lê a carta-poema de Robert Desnos - escrita para sua amada pelo poeta surrealista francês pouco antes de morrer num campo de extermínio nazista - como se esta de Ventura fosse.

\footnotetext{
5 Juventude em marcha (2006). À esquerda, Ventura e Lento no Casal da Boba, no apartamento incendiado por Lento. À direta, Ventura em seu barraco revivendo, anacronicamente, uma de suas trágicas lembranças.
} 
Costa acaba por proporcionar o encontro de espaços e tempos pelo choque dialético das qualidades e temporalidades dos vestígios, e como não, das contradições que implicam os fenômenos que lhos produziram. Com efeito, todos os resíduos inventariados por Costa se colocam em diálogo e a narrar, são diferentes formas de experienciar o processo de reificação da exploração neocolonialista, seja pela arquitetura de detritos, seja pela reciclagem de utensílios residuais, podem mesmo ser palavras que involuntariamente denotam um estado de violência, ou um punhado de memórias turvas e traumáticas em processo de apagamento. Quanto a isso ressalta Costa:

[...] sempre gostei muito de ouvir falar crioulo. Achava bonito chegar a um café, em Benfica, e ouvir uma língua que me era estranha. Hoje, ouve-se muito menos, pois está muito mais confinado aos bairros [...] isso aconteceu porque este sistema capitalista consegue pará-lo, está feito para isso [...] leva a que cada vez mais os cabo-verdianos falem português, em vez de crioulo. E cada vez ensinam menos os filhos a falá-lo, porque se falarem português têm acesso mais fácil a um emprego. (POIARES; SILVA, 2010).

Foi na perspectiva de se contrapor a esse projeto do chamado mundo civilizado que Costa realizou um inventário de poesia, barbárie e memória - os restos de heroína nas agendas telefônicas de Vanda; Ventura que é assombrado por fantasmas, sejam eles seus compatriotas, que vivenciam performaticamente suas memórias da exploração, sejam os fantasmas das esperanças perdidas na Revolução dos Cravos ou da violência da tecnologia da morte do exército fascista de Salazar; ou Vitalina Varela, que chega à Lisboa com um atraso de 25 anos e tudo que encontra são parcos vestígios de seu marido morto. E todas estas experiências inventariadas são oferecidas por meio da fluidez dos frouxos laços dramatúrgicos, notadamente em Juventude em marcha (2006), Cavalo Dinheiro (2014) e Vitalina Varela (2018). O que nos conduz pela experimentação destas obras não é exatamente o rígido e linear progresso de causa e consequência de uma clássica dramaturgia, mas certa aleatoriedade que parece constituir uma exposição das singulares existências e experiências dos moradores dos guetos de Lisboa. 
Figura 03 - Anacronismos: depósitos humanos e invisibilidades ${ }^{6}$

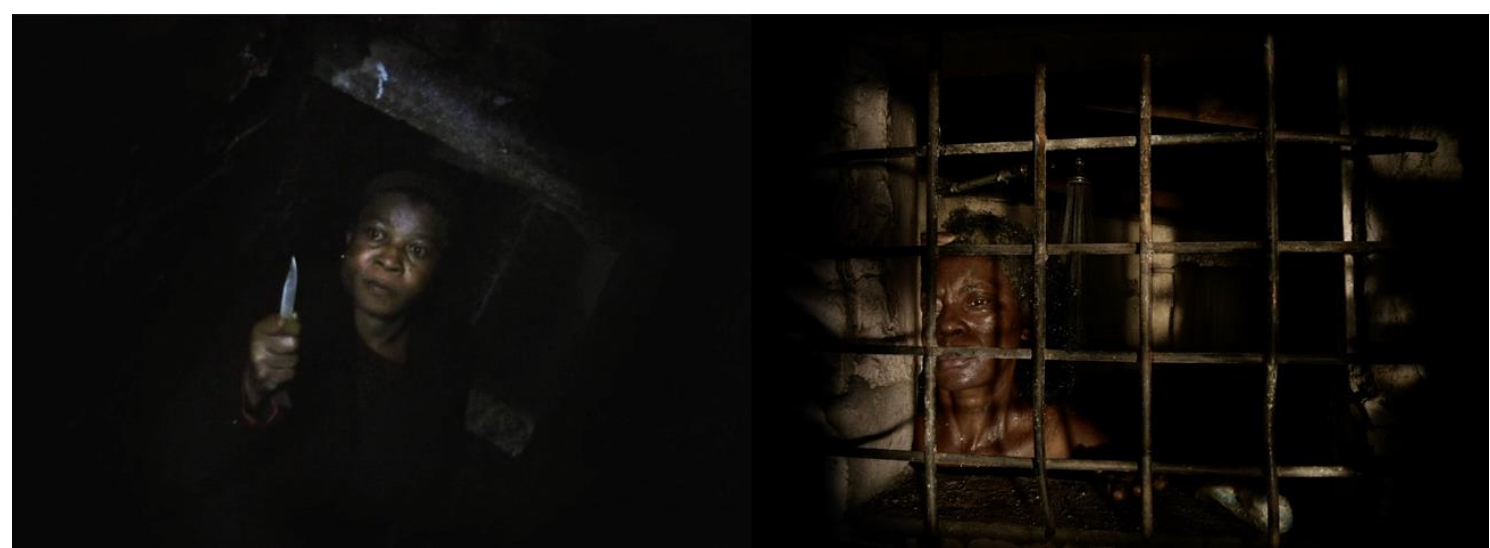

Fonte: Juventude em marcha (2006) e Vitalina Varela (2018).

\section{Poética da mutação, estética dos resíduos}

Em certa entrevista Costa elucida seu mal-estar: “[...] também escolhi ir para lá filmar, porque ali não há qualquer hipótese de eu dizer 'silêncio', 'corta' ou 'acção'. Aquilo está a andar e eu apanho o comboio em andamento" (POIARES; SILVA, 2010, grifo do autor). Assim, Costa reinveste suas imagens: recolhe as imagens rôtas dos detritos que as zonas de poder geram e despojam por onde passam - Fontainhas, Amadora, etc. Suas imagens, doravante magnetizadas pelos detritos e resíduos de toda espécie, compreendem que correspondem exatamente à introdução no programa dos bits corrompidos dos aparelhos.

Agora o que interessa a Costa é toda uma produção residual serializada pelo projeto civilizatório. Uma memória trágica - incontáveis memórias -, um corpo em decomposição, sonhos esfacelados, documentos - vários documentos -, o obituário de Joaquim Brito Varela, a carta de Robert Desnos, aliás, as performances de Ventura, que tantas vezes emergem de um exacerbamento do real em suas fantasmagorias, ora como pai de um grande séquito de seres-resíduos, ora como uma espécie de esquizofrênico aprisionado num sanatório/masmorra/Bastilha/senzala a conversar e ser perturbado por outros tantos fantasmas do neocolonialismo ocidental, sejam militares salazaristas, ou mortos que incidem sobre seu sentimento de culpa, ou ainda como pastor de uma igreja sem fiéis que se esforça a acalentar Vitalina Varela e sua única palavra de consolo é dizer-lhe que "precisa aprender a falar português, pois Deus não entende o crioulo" (VITALINA VARELA, 2018).

\footnotetext{
6 À esquerda, Clotilde em sua aparição em Juventude em marcha (2006) nas Fontainhas. À direta, Vitalina a banhar-se em Vitalina Varela (2018), gueto da Amadora.
} 
Uma gama de vestígios grita e o realizador lusitano se pôs há escutar, decifrar e materializálos em bits.

De No quarto da Vanda (2000) à Vitalina Varela (2018), estamos expostos à personagens que reclamam por seus sujeitos ingovernáveis. Logo no início de Cavalo Dinheiro (2014), prostrado numa cama de hospital, Ventura, enquanto performa sua loucura, diz:

\begin{abstract}
Lembra-se de nossos companheiros? Delgado. Um datilógrafo. Uma noite, ele terminou o seu jantar, colocou seus filhos na cama, em seguida, queimou sua casa. Nunca abriu a boca novamente. Benvindo, seu sobrinho [...] ele sofreu muito com crises epilépticas. Num canteiro de obras, uma viga caiu em sua cabeça e ele caiu do terceiro andar. Lento. Teve que vender drogas para compensar seus salários com uma empreiteira [...] um dia, ele esfaqueou um policial em um ataque. Eles o algemaram e levaram para o esquadrão. Agora ele precisa de um choque por dia para acalmar seus nervos. Para sempre. 0 que os soldados fazem com a gente? Nós continuaremos caindo do terceiro andar. Nós continuaremos sendo esmagados pelas máquinas. Nossa cabeça e pulmões continuarão sofrendo o mesmo. Seremos queimados. Ficaremos loucos. Esse é todo o molde para as paredes de nossas casas. (CAVALO DINHEIRO, 2014).
\end{abstract}

Em certa altura, em Juventude em marcha (2006), Ventura visita Paulo, o coxo, português branco e toxicodependente a quem ele chama de filho e parte a sua procura pelos bairros de lata. Paulo narra-lhe como fora terrível o encontro com sua mãe, quando, na companhia de Nhurro, andavam ambos com os escalpes pendurados e os picos à mostra. Ventura pergunta como pode ajudar e Paulo, deitado na maca em situação pós-operatória, pede a Ventura que o leve à sua mãe e Ventura, então, lhe diria:

Dona Lurdes lembra deste rapaz? Este rosto lhe diz alguma coisa? Estes cabelos todos sujos, estas mãos negras de frio, estas pernas cheias de balas, não foi a senhora que o banhou [...] que o buscava no barril em que ele dormia [...] e essas lágrimas agora? De remorso? Vim trazer-lhe seu filho, tal como ele é. (JUVENTUDE EM MARCHA, 2006).

Costa impregna suas imagens da potência que a máquina-cinema destina aos depósitos de refugos, ou como afirmara Ventura, suas tragédias, seu regime residual, é o molde para as paredes, a argamassa da arquitetura deste mundo: "Esses personagens são aqueles que produzem buracos ou borrões nos programas [...] que escapam tanto da norma 
majoritária, como da contra norma minoritária tal como esta é cada vez mais bem roteirizada pelos poderes" (COMOLLI, 2008, p. 173).

Suas personagens causam "buracos nos programas" e indesejáveis "borrões" nas narrativas hegemônicas. Tornam visível uma série de invisibilidades: sejam os vetores de poder constituintes da máquina-cinema - o enunciado do não dito do dispositivo -, sejam os refugos humanos - alguns destes dispositivos têm como estratégia a invisibilidade tanto da produção quanto do produto. Costa percebe que o programa não suporta seus próprios resíduos e nisso está o poder de seu desmonte, tendo como fonte as contradições execráveis que o aparelho gera.

Quanto a isso, Zygmunt Bauman (2005) constata que vivemos um processo de exacerbação de fronteiras, sejam elas físicas e volúveis ou imateriais. Os centros hegemônicos da cultura e dos signos da economia política adotam cada vez mais medidas que têm como resultados a produção de refugo, resíduo ou lixo humano. As vidas são descartadas à medida que já não se adequam à linguagem fluída e transitória desses centros de poder. Surge uma nova classe de operários, os funcionários das fronteiras (BAUMAN, 2005), que selecionam, classificam, reciclam como peças sobresselentes e/ou descartam estes refugos para zonas suficientemente sombrias e distantes para que não perturbem o desenvolvimento idealizante da vida em estufa.

Costa reinveste suas imagens nas fronteiras e em seus movimentos incessantes: a criação e a destruição das Fontainhas e a impossibilidade de reciclagem de seus corpos ingovernáveis. Não à esmo que a fotografia de Leonardo Simões, a partir de Juventude em marcha (2006), torna-se cada vez mais claustrofóbica e sombria. A luz que penetra no Casal da Boba é intensa, a câmera faz às vezes de uma câmera de vigilância e registra a verborragia de Vanda - aliás, não teria o Casal da Boba certo aspecto panóptico de um poder que vê, mas invisibiliza as marginalizações que ele mesmo criou? Mas Ventura não está totalmente certo da mudança para as habitações sociais, sua casa é vazia, preenchida apenas pela brancura. Ele nos conduz pelas fronteiras a nos apresentar os corpos-resíduos. E quanto mais adentramos neste mundo - aqui tudo é detrito, uma mesa, uma garrafa, um olhar, Nhurro recolhendo lixo, Benvindo numa fábrica abandonada, demasiadas paredes decrépitas, os sons e o fora de campo - tanto mais sombrio a fotografia se torna, posto que a luz da visibilidade hegemônica aqui é impenetrável. 
Figura 04 - Corpos sob sombras ${ }^{7}$

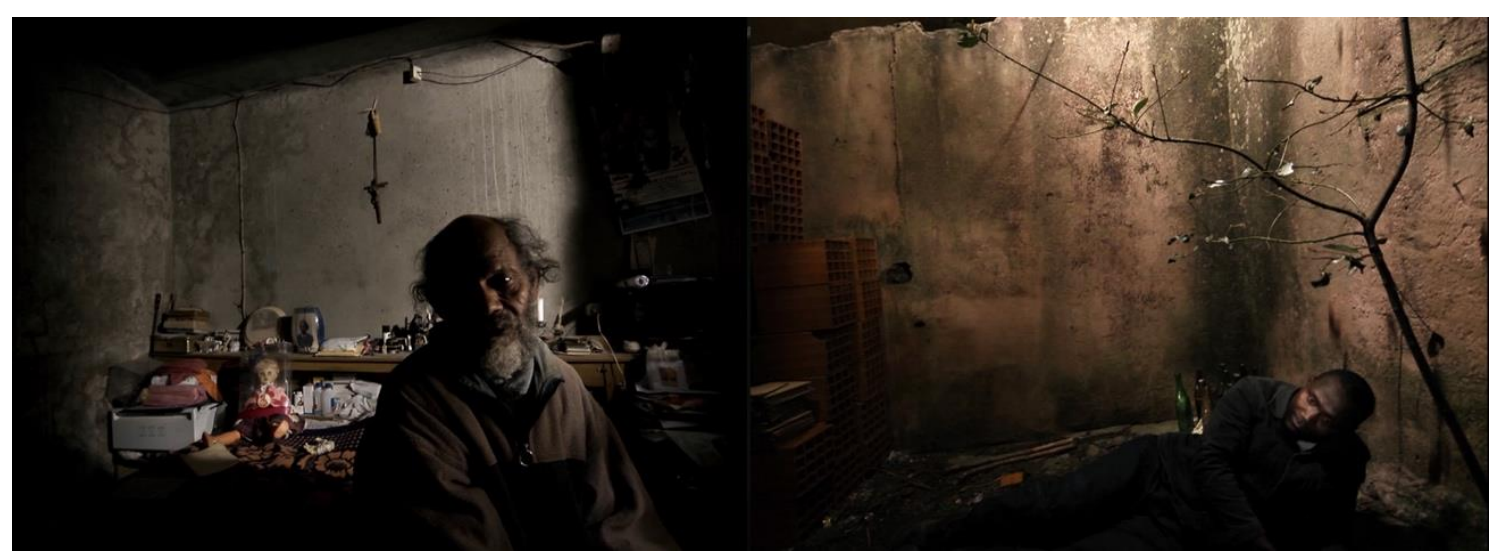

Fonte: Cavalo Dinheiro (2014).

Em Cavalo Dinheiro (2014), Ventura fora largado num hospital psiquiátrico cuja composição fotográfica e a seleção arquitetônica-sígnica-imagética constroem um espaço mórbido de um depósito humano, que faz as vezes de uma masmorra, uma senzala, porões de uma ditadura ou um hospital no século XXI - todos locais constituídos como tecnologias de poder e morte. A plasticidade da fotografia nos permite aludir Goya em sua tela Hospital de apestados - escombros cuja luz quase não penetra, espaços em que o Estado e as forças em questão isolam para invisibilizar -, e sobre a obscenidade do poder Costa joga uma luz focal num gesto de desmonte.

Figura 05 - Depósito de obscenidades da civilização ${ }^{8}$

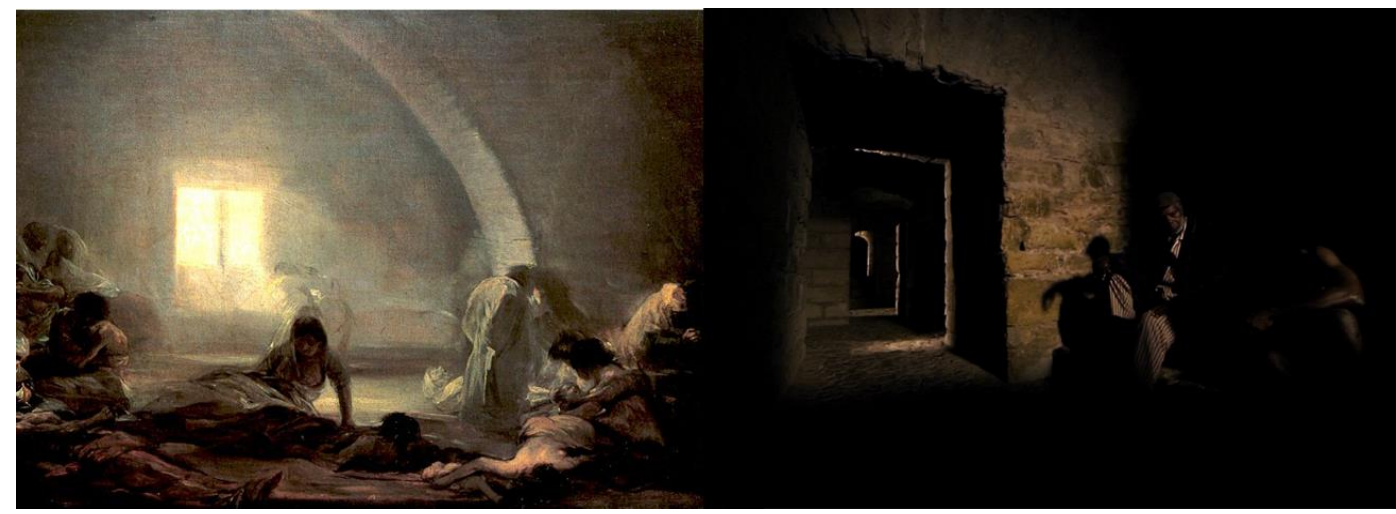

Fonte: Goya (1810) e Cavalo Dinheiro (2014).

\footnotetext{
${ }^{7}$ Cavalo Dinheiro (2014).

8 À esquerda, Hospital de apestados, Goya, 1810. À direta, Ventura circula pelos corredores-masmorras de um hospital psiquiátrico em Cavalo dinheiro (2014).
} 
Em seu gesto de contra programação, Pedro Costa passa a narrar a história da produção dos refugos lusitanos, história da produção da economia política, a partir, também, e sobretudo, dos dados sensíveis dos resíduos e seus vestígios. Quando Costa decidiu filmar na Ilha de Santiago, em Tarrafal, esboçava-se ali um primeiro gesto seu de transgressão ao programa. Mas era preciso ainda compreender que no projeto da redundância das representações programadas, o programa esvazia-se pouco a pouco, em cada realização de suas virtualidades inscritas, até que, esgotado o sistema, este tenha sua energia dissipada e caia em total esfriamento. Entretanto, a rebeldia é valor inscrito no programa. Este se alimenta da apropriação de imagens e discursos que não desvalidem suas imanências.

O programa prevê uma rebeldia consentida - correntes longas, decerto, porém correntes -, gestos que toquem sutilmente, mas não abalem sua organização, sua linguagemestratégia: um processo de apropriação metabólica de certos discursos, que, pela fragilidade ou esvaziamento de significados, os filtros transformam (desregulam) e os inscrevem em seu acervo para que o programa não morra de inanição. A rebeldia consentida é prenhe de informações relativamente novas, que são envelhecidas e empobrecidas em altíssima velocidade (FLUSSER, 2008), ou seja, uma falsa transgressão com a qual o programa se alimenta como ato reformista e acaba por reivindicar velhas abjeções hordásticas em novos projetos civilizatórios. Assim procede o metabolismo das mise-en-scènes midiatizadas das tecnoimagens. Mas Costa potencializa suas subversões para não ser engolido por esse deus Cronos.

O real seria, aquela parte do mundo que não é apreendida em nenhuma narrativa, que escapa a todas as narrativas já formadas. Que demanda uma nova, ou desafia a narrativa. Real - o que já está aqui sem ser apreensível e que nos apreende, a nós, sob a forma de acidente, lapso, surpresa, gag, pane, afasia, silêncio ou grito. (COMOLLI, 2008, p. 100).

Imaginemos o perigoso encontro do improvável, do imprevisível, da forma nova, da nova informação: são características de extrema singularidade, inapropriadas, choque de genes estranhos, acidente, mutação. E para tanto, Costa deixa para traz o processo industrial e muta-se em artesão. Lança-se contra a matéria residual, que sempre esteve aqui, mesmo que ruidoso e para além das fronteiras. A mutação acaba por dar-se em cadeia: o encontro gerado não só provoca a precipitação do artesão, mas de uma série de mutações, como a 
máquina-cinema em cinematógrafo - aparelho aberto para a captura dos fenômenosrejeitos -, o personagem - prenhe de know how em seu corpo oco dessubjetivado -, mutado em sujeitos narradores - vestígios vivos da história dos detritos e corpos ingovernáveis.

0 artesão move-se a procura dos detritos cuja economia das imagens não conseguiu digerir e expande a realidade que dantes, soterrada pela inflação das máquinas, prostrava-se alienada. É em Juventude em marcha (2006) e em suas obras seguintes, sobre as ruínas das Fontainhas e guetos de Lisboa, que Pedro Costa desenvolve, com ainda mais vigor, sua estética do residual. Ele expande a realidade, pois joga contra o programa:

Auschwitz é a realização da nossa cultura. [...] A nossa cultura deixou cair sua máscara mistificadora [...] e mostrou seu verdadeiro rosto. Rosto de monstro objetivador do homem. 0 que caracteriza o campo de extermínio é precisamente de não se tratar de evento 'superável', mas de primeira realização de uma virtualidade inerente no projeto ocidental, e que se repetirá sob outras formas. (FLUSSER, 2011b, p. 21-24, grifo nosso).

\section{Referências}

AGAMBEN, Giorgio. 0 poder soberano e a vida nua: homo sacer I. Belo Horizonte: UFMG, 2012.

AGAMBEN, Giorgio. 0 que é o contemporâneo e outros ensaios. Chapecó: Argos, 2009.

BAUMAN, Zygmunt. Vidas desperdiçadas. Rio de Janeiro: Jorge Zahar, 2005.

BENJAMIN, Walter. Obras escolhidas I. São Paulo: Brasiliense: 1996.

BENJAMIN, Walter. Passagens. Belo Horizonte: Ed. UFMG, 2009.

BENJAMIN, Walter. 0 anjo da história. Lisboa: Assírio \& Alvim, 2010.

CABO, Ricardo Matos (Org.). Cem mil cigarros: os filmes de Pedro Costa. Lisboa: Orfeu Negro, 2009.

CASA DE LAVA. Direção: Pedro Costa. Roteiro: Pedro Costa. [Portugal], 1994. (110 min), estéreo, cor.

CAVALO DINHEIRO. Direção: Pedro Costa. Roteiro: Pedro Costa. [Portugal], 2014. (103 min), estéreo, cor.

COMOLLI, Jean-Louis. Ver e poder. Belo Horizonte: Ed. UFMG, 2008.

DELEUZE, Gilles. 0 mistério de Ariana. Lisboa: Passagens, 2015. 
DIDI-HUBERMAN, Georges. Diante do tempo: história da arte e anacronismo das imagens. Belo Horizonte: Editora UFMG, 2019.

FISCHER, Ernest. A necessidade da arte. Rio de Janeiro: Zahar, 1987.

FOUCAULT, Michel. Microfísica do poder. Rio de Janeiro: Paz\&Terra, 2018.

FLUSSER, Vilém. Filosofia da caixa preta. São Paulo: Annablume, 2011a.

FLUSSER, Vilém. Pós-história. São Paulo: Annablume, 2011b.

FLUSSER, Vilém. 0 universo das imagens técnicas. São Paulo: Annablume, 2008.

GOYA, Francisco de. Hospital de apestados. Madri, 1810. 1 pintura óleo sobre tela.

JUVENTUDE EM MARCHA. Direção: Pedro Costa. Roteiro: Pedro Costa. [Portugal], 2006. (156 min), estéreo, cor.

MARX, Karl. Para a crítica da economia política. São Paulo: Nova Cultural, 1999.

MARX, Karl. 0 Capital: Livro I. São Paulo: Boitempo, 2013.

MBEMBE, Achille. Necropolítica: biopoder, soberania, estado de exceção, política da morte.

São Paulo: N-1 Edições, 2018.

NO QUARTO DA VANDA. Direção: Pedro Costa. Roteiro: Pedro Costa. [Portugal], 2000. (180 min), estéreo, cor.

OSSOS. Direção: Pedro Costa. Roteiro: Pedro Costa. [Portugal], 1997. (157 min), estéreo, cor.

PELBART, Peter Pál (Org.). A nau do tempo-rei. Rio de Janeiro: Imago, 1993.

POIARES, Marta, SILVA, Pedro Dias da. Pedro Costa: Prémio Universidade de Coimbra "Este não é o meu país. O meu país é as Fontaínhas". Coimbra, 2010. Disponível em: http://pedrocosta-heroi.blogspot.com.br/2010/09/pedro-costapremio-univers idade-de.html. Acesso em: 12 out. 2020.

SALES, Michelle. 0 cinema e o direito à morte: Cavalo Dinheiro, de Pedro Costa. Novos Olhares, São Paulo, v. 8, n. 1, p. 61-72, julho 2019.

VITALINA VARELA. Direção: Pedro Costa. Roteiro: Pedro Costa. [Portugal], 2014. (130 min), estéreo, cor. 


\title{
The disassembly of the cinema-machine: Pedro Costa and the aesthetic of residual
}

\begin{abstract}
At the end of Ossos (movie from 1997), filmed in Fontainhas, Lisbon's ghetto of Cape Verdeans, Pedro Costa feels affected by his experiences in the neighborhood and sees his affects not materialized in his images. Between Costa and the "Fontainhas" phenomenon there was the cinema machine: a machine power that deregulates bodies and phenomena and recomposes them in an image regime incapable of giving visual shape to residual realities. According to researchers who dialogue with the theory of images - Jean-Louis Comolli, Gilles Deleuze, Giorgio Agamben, Vilém Flusser, among others - the technologies of power, and here we emphasize the media-imagery devices, manage the symbolic production of a determined reality, and have as strategy to produce subservient subjectivities (or desubjectivations) for the benefit of a determined political project. We bet that Costa, above all in Juventude on the march (movie from 2006), when establishing a political-aesthetic method for a subversive regime of images, his aesthetic of the residual, will manage a series of strategies to effect a disassembly - at least a reassembly - of the cinema machine.
\end{abstract}

\section{Keywords}

Pedro Costa. Cinema-machine. Technical images. Desubjectivation. Aesthetics of the residual.

\section{Autor correspondente}

Osmar Gonçalves dos Reis Filho osmargoncalves@hotmail.com

\section{Como citar}

REIS FILHO, Osmar Gonçalves; AGUIAR, David Leitão. O desmonte da máquina-cinema: Pedro Costa e a estética do visual. Intexto, Porto Alegre, n. 52, e-109802, jan./dez. 2021.

DOI: http://dx.doi.org/10.19132/1807-8583202152.109802

Recebido em 15/10/2020

Aceito em 15/03/2021

(c) (1) (9) 